\title{
Fabrikasi Mirror-like Surface Bahan Commercially-pure Titanium (CP-Ti) Menggunakan Metode Electropolishing Untuk Aplikasi Biomedis
}

\author{
M.A. Setyawan ${ }^{1, *}$, G.S. Prihandana ${ }^{2}$, M. Mahardika ${ }^{1}$ \\ 1Departemen Teknik Mesin dan Industri, Fakultas Teknik, Universitas Gadjah Mada \\ Jalan Grafika No. 2 Yogyakarta 55281 Telp. +62-274-521673 \\ 2Departemen Fisika, Fakultas Sains dan Teknologi, Universitas Airlangga, Kampus C Mulyorejo, Surabaya -60115 \\ e-mail: *1 mandresetyawan@gmail.com
}

\begin{abstract}
Abstrak
Microfilter adalah sebuah perangkat micro-dialysis yang telah terbukti efisien dalam membuang limbah metabolik seperti urea, asam urat, dan kreatinin dari darah. Perangkat microfilter dibuat dengan merakit metal structural layer dan membran nanoporous polyethersulfone. Dalam penelitian ini, metal structural layer yang desainnya telah dimodifikasi dengan mengadopsi bentuk mazeshaped difabrikasi menggunakan wire-EDM. Kemudian metode electropolishing diimplementasikan pada metal structural layer bahan commercially-pure titanium (CP-Ti) untuk menghasilkan kualitas permukaan yang mengkilap atau mirror-like surface. Mirror-like surface dibutuhkan untuk mencegah biofouling, yaitu mengendapnya komponen darah pada bagian dinding atau side-wall pada metal structural layer. Mirror-like surface berhasil diperoleh pada parameter tegangan $20 \mathrm{~V}$, gap $10 \mathrm{~mm}$, penambahan $20 \mathrm{vol} . \%$ ethanol pada larutan elektrolit dan waktu proses 5 menit. Surface roughness minimum yang terukur menggunakan stylus profilometer adalah $\mathrm{Ra}=0,227 \mu \mathrm{m}$.
\end{abstract}

Kata kunci: Electropolishing, Titanium, Microfilter, Mirror-like surface, Etbylene Glycol.

\begin{abstract}
Microfilter is a micro-dialysis device that has been proven to be efficient in removing metabolic wastes such as urea, uric acid, and creatinine from the blood. Microfilter devices are made by assembling metal structural layers and nanoporous polyethersulfone membranes. In this study, a metal structural layer has been modified by adopting a maze-shaped shape fabricated using wire-EDM. Then the electropolishing method is implemented in the structural metal layer of commercially pure pure titanium (CP-Ti) to produce a mirror-like surface. Mirrorlike surface is needed to prevent biofouling, which is to settle the blood component on the wall or side walls in the metal structural layer. Mirror-like surface was successfully obtained on $20 \mathrm{~V}$ voltage parameters, $10 \mathrm{~mm}$ gap, adding 20 vol.\% Ethanol to electrolyte solutions and a 5 minute process time. The minimum surface roughness measured using a stylus profilometer is $\mathrm{R} a=0.227 \mu \mathrm{m}$.
\end{abstract}

Keywords: Electropolishing, Titanium, Microfilter, Mirror-like surface, Ethylene Glycol.

\section{PENDAHULUAN}

Dialisis merupakan suatu terapi yang dikembangkan untuk menolong pasien dengan penyakit ginjal stadium akhir, namun pasien harus menjalani terapi dialisis tersebut dirumah sakit selama kurang lebih 4 jam, tiga kali per minggu (To et al., 2015). Untuk mengurangi 
frekuensi terapi dialisis di rumah sakit, dikembangkanlah Wearable Artificial Kidney (WAK), sebuah alat dialisis yang dapat dioperasikan saat dikenakan oleh pasien. WAK tersebut lebih fleksibel dan portable dibandingkan dengan mesin terapi dialisis konvensional. Selain itu, terapi menggunakan WAK dapat dilakukan kapanpun dan dimanapun pasien berada, sehingga tidak mengganggu aktifitas sehari-hari. Dengan demikian, WAK dapat meningkatkan kualitas hidup pasien gagal ginjal (Gu dan Miki, 2009).

WAK terdiri dari dua komponen utama: dialyzer adalah salah satu komponen pada sistem dialisis yang menentukan performa dan efektifitas dari proses filtrasi darah dan dialysate filter yang berfungsi memisahkan cairan dialysate dengan zat sisa metabolisme agar cairan dialysate dapat digunakan kembali dalam proses filtrasi darah (Gu dan Miki, 2009).

Salah satu focus pengembangan WAK dewasa ini adalah pada bagian microfilter yang digunakan sebagai dialyzer. Microfilter tersebut terdiri dari dua bagian utama. Bagian pertama adalah struktur layer yang terbuat dari bahan metal, berfungsi sebagai ruang mikro (micro chamber) yang digunakan sebagai tempat aliran darah dan atau aliran cairan pemisah zat sisa (dialysate). Bagian kedua adalah membran yang terbuat dari polyethersufone (PES), berfungsi sebagai pemisah zat sisa dan nutrisi dalam darah (Gu dan Miki, 2009).

Ota et al (2017), melakukan penelitian invitro untuk mengevaluasi performa microfilter. Namun, hasil penelitian ini menunjukan terjadinya penurunan performa dialysis yang disebabkan oleh menempelnya partikel darah dan zat sisa metabolisme pada dinding (sidewall) struktur layer karena tingkat kekasaran permukaan (surface roughness) yang tidak sesuai.

Sifat permukaan (surface properties) dari material implant berperan sangat penting terhadap biokompatibilitas, fungsi dan keselamatan dalam penggunaannya. Oleh karena itu, surface treatment telah diaplikasikan pada material implant untuk memperbaiki tekstur permukaan maupun sifat kimiawi sehingga tidak membahayakan lingkungan biologis disekitar implant. Di antara berbagai jenis surface treatment, electropolishing (EP) merupakan metode yang dapat digunakan untuk meningkatkan ketahanan korosi dan biokompatibilitas material implant. Electropolishing ini juga dapat diaplikasikan pada benda dengan bentuk yang kompleks (Sajjad $\mathrm{dkk}, 2014)$.

Penelitian ini difokuskan pada bagian lapisan material yang terbuat dari bahan titanium. Titanium menjadi bahan biomaterial yang populer dibidang aplikasi medis. Titanium dan paduannya cocok untuk digunakan sebagai material implant karena sifat tahan karatnya yang baik dan rasio strength-to-weight yang tinggi dibandingkan dengan stainless steel dan paduan Co-Cr (Mahyudin dan Hermawan, 2016). Karena digunakan pada proses dialysis, struktur lapisan titanium ini harus memiliki tingkat kekasaran permukaan yang sesuai agar tidak menghambat aliran darah.

Pada penelitian ini, dilakukan proses electropolishing untuk memperhalus permukaan bagian sisi samping dialiser berbahan titanium. Permukaan sisi samping yang halus diharapkan dapat mengurangi terjadinya pengendapan komponen darah pada permukaan side-wall struktur layer yang disebut biofouling. 


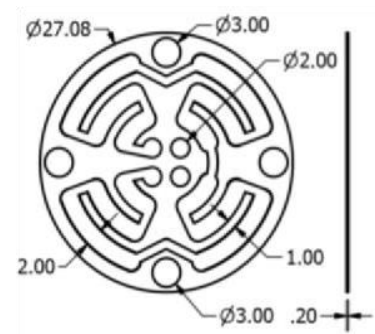

(a)

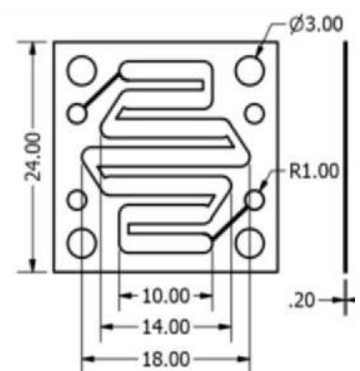

(b)

Gambar 1.a. Desain Structural Layer (Setyawan dkk, 2016) b. Desain Structural Layer (Gu dan Miki, 2009)

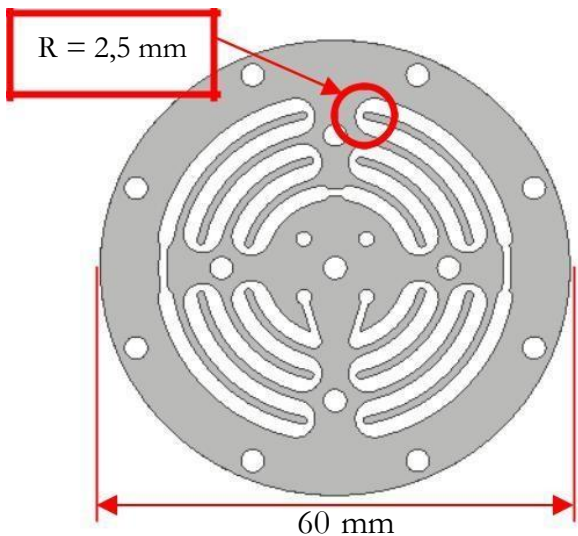

Gambar 2. Structural layer titanium

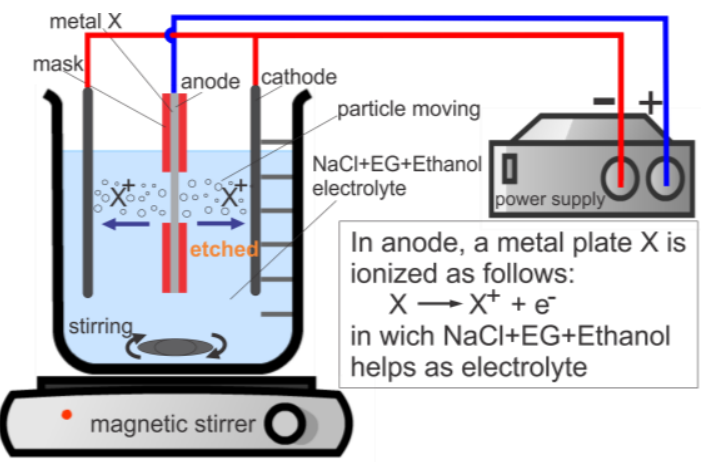

Gambar 3. Experimental set-up proses electropolishing plat titanium

\section{METODE PENELITIAN}

\subsection{Desain Dialiser}

Plat titanium (CP-Ti) dengan ketebalan $200 \mu \mathrm{m}$ (Nilaco Co., Japan) digunakan sebagai structural layer dalam microfilter, penulis telah berhasil membuat structural layer dengan adsorption area yang lebih luas. Pada penelitian yang dilakukan oleh Gu dan Miki (2009), structural layer memiliki total adsorption area sebesar $144 \mathrm{~mm}^{2}$. Gambar $1 \mathrm{~b}$ menunjukan desain structural layer 
yang dibuat oleh Gu dan Miki (2009). Penulis menggunakan luas area structural layer yang sama dan memodifikasi bentuk dari adsorption area, yang mengadopsi bentuk maze. Harapannya, dengan luas adsorption area yang lebih luas, maka dapat meningkatkan performa sistem dialisis pada microfilter dengan menyaring lebih banyak zat sisa metabolisme. Total luas adsorption area pada structural layer yang penulis desain adalah $192 \mathrm{~mm}^{2}$ (Gambar 1a). 30\% lebih luas dibandingkan dengan desain sebelumnya (Gambar 1b).

Pada penelitian ini, penulis mengembangkan desain structural layer hasil dari penelitian pada tahun 2016. Diameter structural layer 50 - $60 \mathrm{~mm}$ dipilih dengan tujuan untuk memperluas area difusi pada setiap lapisnya. Dimensi diameter dibatasi tidak terlalu besar karena ukuran microfilter berpengaruh terhadap fleksibilitasnya sebagai ginjal buatan yang portable. Selain itu, konsep WAK ke depannya diharapkan dapat menjadi acuan dalam pengembangan Implantable Artificial Kidney (IAK), sehingga ukuran microfilter tidak melebihi ukuran ginjal manusia (Gu dan Miki, 2009). Hal tersebut juga yang menjadi alasan dipilihnya bentuk lingkaran, sehingga pada pengembangannya untuk IAK nantinya akan lebih aman bagi organ-organ lain di dalam tubuh ketika diimplan, dibanding dengan bentuk persegi yang memiliki sisi yang menyudut sehingga rentan bagi organ di sekitarnya.

Rancangan structural layer titanium pada penelitian ini ditunjukkan oleh Gambar 2. Pada rancangan tersebut, didapat total area penyerapan sebesar $792,928 \mathrm{~mm}^{2}$. Selain itu, perbaikan juga dilakukan pada curved area (lingkaran merah). Desain kurva pada Gambar 1a masih menggunakan curvature radius $1 \mathrm{~mm}$, kemudian diubah menjadi 2,5 mm (Gambar 2). Perubahan radius pada curved area ini didasari dari penelitian Ota et al (2016) bahwa curved area 2,5 mm lebih meminimalkan terjadinya biofouling dibandingkan dengan $1 \mathrm{~mm}$.

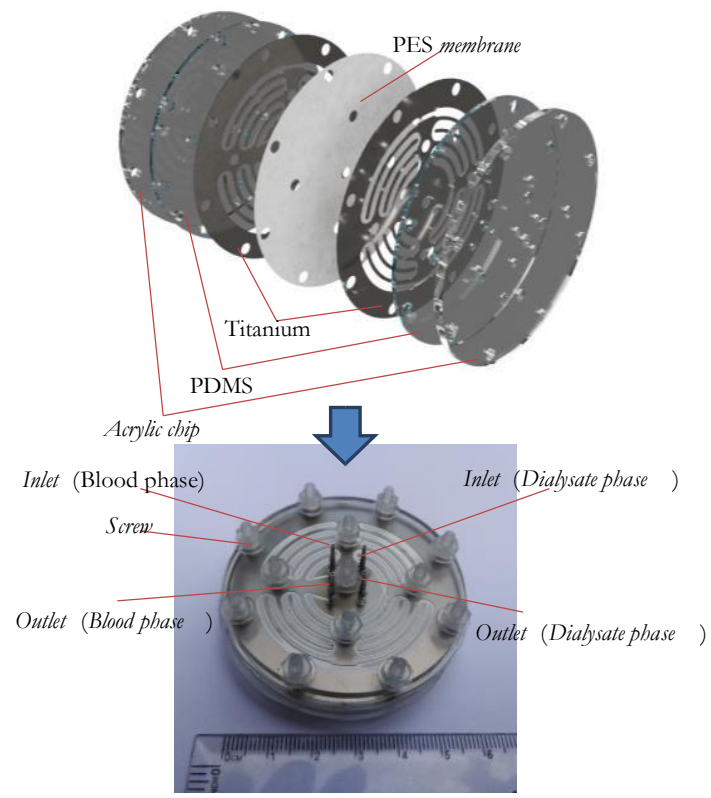

Gambar 4. Skema perakitan unit microfilter 
Tabel 1. Parameter electropolishing.

\begin{tabular}{ll}
\hline Parameter & \multicolumn{1}{c}{ Value } \\
\hline $\begin{array}{l}\text { Voltage } \\
\text { Anode }\end{array}$ & $10,20,30 \mathrm{~V}$ \\
& Commercially-pure Titanium (Nilaco Co., Japan) \\
Electrolyte solution & Ethanol (0,10,20 vol. \%) \\
& $1.0 \mathrm{M} \mathrm{NaCl}$ \\
& $99.0 \%$ ethylene glycol \\
Time & 5 minutes \\
Working gap & 10 mm \\
Cathode & Stainless Steel 316L \\
\hline
\end{tabular}

\subsection{Fabrikasi Structural Layer}

Material titanium sheet dipotong sesuai dengan pola desain menggunakan wire-EDM. Kondisi permukaan hasil dari proses EDM biasanya kurang baik dan memerlukan proses polishing untuk mendapatkan surface finish yang mengkilap (Wong et al, 1998). Metode electropolishing dipilih karena cocok untuk structural layer yang tipis dan memiliki bentuk geometri yang komplek.

Metode electropolishing digunakan untuk memproses berbagai jenis material yang bersifat konduktor listrik. Proses tersebut menggunakan prinsip Faraday, yaitu jika ada dua logam elektroda direndam dalam larutan elektrolit dan dihubungkan dengan sumber arus DC, maka partikel logam akan terlepas dari anode dan kemudian akan tertarik ke cathode (Gambar 3).

Pengujian electropolishing dilakukan dengan melakukan berbagai percobaan dengan berlandaskan pada beberapa jurnal penelitian untuk mendapatkan parameter (gap, waktu pemesinan, konsentrasi elektrolit dan voltase pada power supply) yang menghasilkan mirror-like surface pada bagian side-wall structural layer titanium. Nominal surface roughness untuk permukaan mengkilap atau glossy berada diantara 0,15 hingga $2 \mu \mathrm{m} \mathrm{R}_{\max }$ (Wong dkk, 1998). Sedangkan menurut penelitian Ota dkk (2016), biofouling menurun secara derastis pada permukaan dengan nilai $\mathrm{R}_{\mathrm{a}}$ kurang dari $1 \mu \mathrm{m}$.

Prosedur percobaan dalam penelitian ini adalah sebagai berikut: benda kerja berupa plat titanium dengan tebal $0,2 \mathrm{~mm}$ dipotong dengan ukuran $50 \times 10 \mathrm{~mm}$ benda kerja dibersihkan menggunakan methanol selama 5 menit menggunakan ultrasonic bath untuk menghilangkan impurity.

Dari hasil try and error didapatkan parameter yang akan digunakan untuk mengelectropolishing struktur layer seperti yang dapat dilihat pada Tabel 1.

\subsection{Perakitan microfilter}

Structural layer titanium yang telah berhasil di-electropolishing dirakit dengan komponen lain yaitu membran PES, Polydimetbylsiloxane (PDMS) dan akrilik. Satu unit microfilter terdiri dari 1 buah membran PES dan dua buah lapisan struktur. Untuk menghindari kebocoran, unit microfilter dimampatkan dan dikencangkan menggunakan 13 buah sekrup. Skema perakitan microfilter ditunjukan oleh Gambar 4. 


\section{HASIL DAN PEMBAHASAN}

Tabel 2. Nilai Ra spesimen Ti setelah proses electropolishing.

\begin{tabular}{|c|c|c|c|c|c|c|c|c|}
\hline No. & E (vol. \%) & $\begin{array}{c}\text { Voltage } \\
\text { (V) }\end{array}$ & $\begin{array}{c}\text { Gap } \\
(\mathrm{mm})\end{array}$ & $\begin{array}{c}\text { Time } \\
\text { (minutes) }\end{array}$ & $\begin{array}{l}\mathbf{R}_{\mathrm{a}} 1 \\
(\mu \mathrm{m})\end{array}$ & $\begin{array}{l}\mathbf{R}_{\mathrm{a}} 2 \\
(\mu \mathrm{m})\end{array}$ & $\begin{array}{l}\mathbf{R}_{\mathrm{a}} 3 \\
(\mu \mathrm{m})\end{array}$ & $\begin{array}{c}R_{a} \text { mean } \\
(\mu \mathrm{m})\end{array}$ \\
\hline 1 & 0 & 10 & 10 & 5 & 1,14 & 1,12 & 1,22 & 1,160 \\
\hline 2 & 0 & 20 & 10 & 5 & 0,58 & 0,60 & 0,68 & 0,620 \\
\hline 3 & 0 & 30 & 10 & 5 & 0,80 & 0,88 & 0,68 & 0,787 \\
\hline 4 & 10 & 10 & 10 & 5 & 0,94 & 0,90 & 1,40 & 1,080 \\
\hline 5 & 10 & 20 & 10 & 5 & 0,62 & 0,60 & 0,44 & 0,553 \\
\hline 6 & 10 & 30 & 10 & 5 & 0,70 & 0,74 & 0,78 & 0,740 \\
\hline 7 & 20 & 10 & 10 & 5 & 0,62 & 0,78 & 0,68 & 0,693 \\
\hline 8 & 20 & 20 & 10 & 5 & 0,20 & 0,22 & 0,26 & 0,227 \\
\hline 9 & 20 & 30 & 10 & 5 & 0,30 & 0,26 & 0,28 & 0,280 \\
\hline
\end{tabular}

Tabel 2 menunjukkan data hasil pengukuran Nilai $\mathrm{R}_{\mathrm{a}}$ spesimen Ti setelah proses electropolishing menggunakan stylus profilometer.

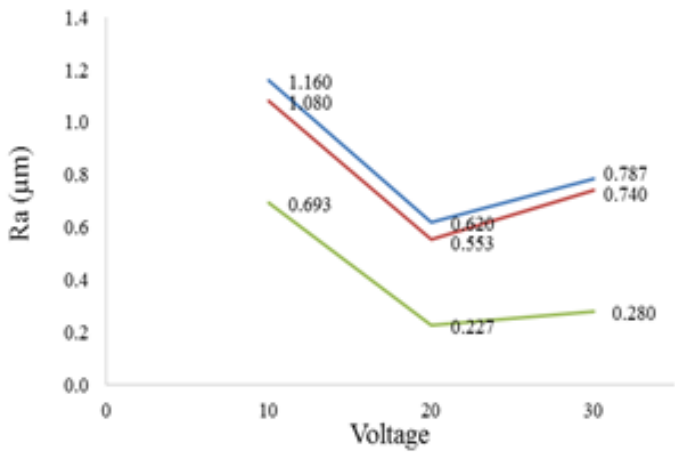

(a)

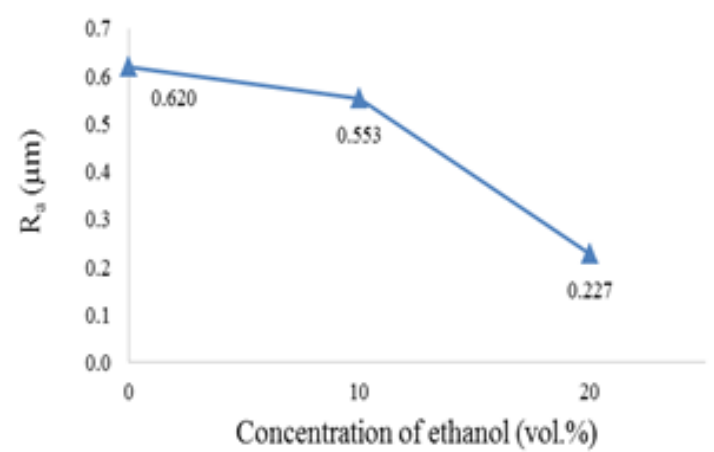

(b)

Gambar 5. Nilai Ra spesimen Ti menggunakan stylus: (a) sebagai fungsi penambahan konsentrasi ethanol terhadap tegangan, dan (b) sebagai fungsi penambahan konsentrasi ethanol terhadap tegangan konstan $20 \mathrm{~V}$.

Gambar 5a menunjukkan nilai Ra dari spesimen titanium setelah proses electropolishing sebagai fungsi penambahan konsentrasi ethanol pada latutan elektrolit terhadap tegangan. Dapat dilihat pada grafik bahwa penambahan ethanol pada larutan elektrolit ethylene glycol$\mathrm{NaCl}$ dapat menurunkan nilai kekasaran permukaan sidewall. Nilai kekasaran terendah diperoleh dengan menambahkan 20 vol. \% ethanol. Seperti yang terlihat pada Gambar 5b ketika tegangan dipertahankan pada $20 \mathrm{~V}$ dan konsentrasi ethanol bertambah, nilai surface roughness turun hingga $\mathrm{R}_{\mathrm{a}}=0,227 \mu \mathrm{m}$.

Namun pada Gambar 5a saat tegangannya dinaikkan menjadi $30 \mathrm{~V}$, nilai surface roughness sedikit meningkat. Maka tegangan $20 \mathrm{~V}$ adalah yang paling optimal untuk mendapatkan nilai kekasaran yang paling rendah. 

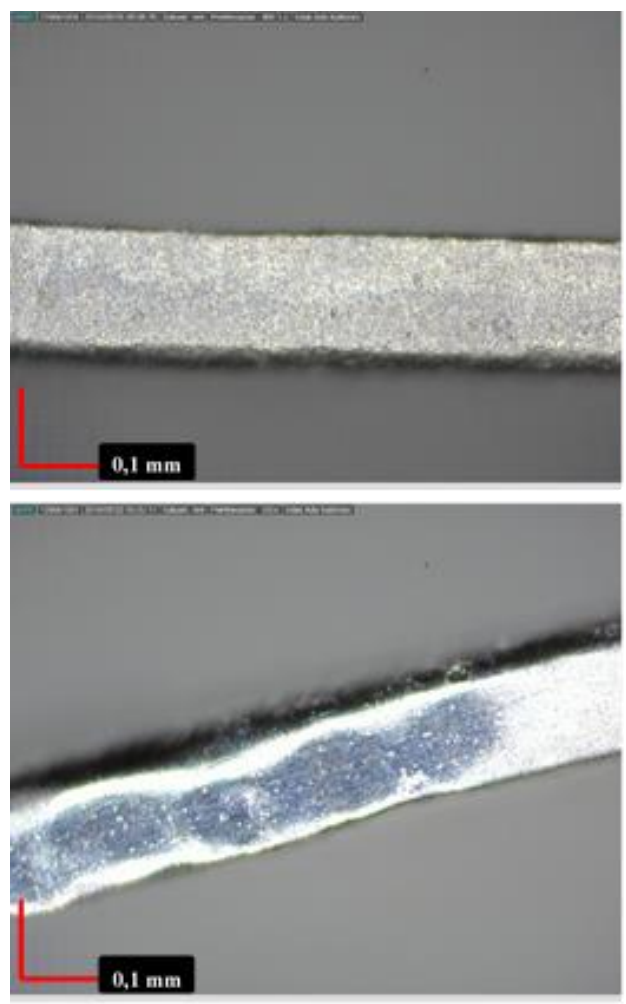

Gambar 6. Image permukaan spesimen Ti hasil electropolishing saat tegangan konstan $20 \mathrm{~V}$

Hasil ini didukung dengan Gambar 6 yang menunjukkan image permukaan spesimen titanium hasil electropolishing saat tegangan disetting konstan pada $20 \mathrm{~V}$. Penambahan ethanol sebanyak 20 vol. \% menghasilkan kualitas permukaan yang paling mengkilap atau disebut juga mirror-like surface.

Donghyun et al, (2015) melakukan penelitian tentang efek penambahan ethanol dalam larutan elektrolit ethylene glycol-NaCl pada electropolishing titanium (GR.2 ASTM B 265). Pada penelitian tersebut dihasilkan bahwa penambahan ethanol lebih dari 20 vol. \% menyebabkan pertukaran elektron antara $\mathrm{Ti}^{4+}$ dan $\mathrm{Cl}^{-}$menjadi non-uniform. Penambahan 20 vol. \% ethanol pada larutan elektrolit ethylene glycol- $\mathrm{NaCl}$ adalah konsentrasi ethanol yang paling optimal untuk electropolishing titanium karena dapat mempertahankan ketebalan lapisan $\mathrm{TiCl}^{4}$ yang cukup pada working electrode.

\section{KESIMPULAN}

Pada penelitian ini telah dilakukan proses surface finish electropolishing pada plat commercially-pure titanium (CP-Ti) di- dalam larutan elektrolit ethylene glycol-NaCl ditambahkan dengan ethanol pada temperatur ruang dan beberapa variasi tegangan. Permukaan side-wall plat titanium dengan tebal $200 \mu \mathrm{m}$ telah berhasil diperbaiki kualitasnya menjadi mirror-like finish dengan menambahkan 20 vol. \% ethanol kedalam larutan elektrolit ethylene glycol-NaCl. Nilai $\mathrm{R}_{\mathrm{a}}$ 0,227 $\mu \mathrm{m}$ berhasil diperoleh dengan mengkombinasikan konsentrasi E20 dengan tegangan 20 V. Permukaan halus pada side-wall titanium hasil electropolishing memungkinkan untuk aplikasinya yaitu kontak dengan darah dalam micro-fluidic channel. 


\section{DAFTAR PUSTAKA}

Ahmad, S., (2009), Manual of Clinical Dialysis, Springer International Publishing, DOI: 10.1007/978-0-387-09651-3, eBook ISBN 978-0-387-09651-3.

Azar, A.T., (2013). Modeling and Control of Dialysis Systems. Springer. ISBN 978-3-64227457-2.

Baroroh, D. K., (2014), Optimasi Electropolishing pada Pembuatan Multi-layered Microfilter dengan Pendekatan Full Factorial Design, Skripsi, Jurusan Teknik Mesin dan Industri, Fakultas Teknik, Universitas Gadjah Mada, Yogyakarta.

Besterfield, D. H.,(2013), Quality Improvement-9th edition, Pearson Education, Inc., publishing as Prentice Hall, ISBN-13: 978-0-13-262441-1.

Cheng, C. Li, S. Zhao, W. Wei, Q. Nie, S. Sun, S. Zhao, C. The hydrodynamic permeability and surface property of Polyethersulfone ultrafiltration membranes with mussel-inspired polydopamine coatings. J. Membr. Sci. 2012, 417-418, 228.

Donghyun, K., Kyungsik S., Dahye S., Yonghwan K., Wonsub C., (2015), Effect of added ethanol in ethylene glycol- $\mathrm{NaCl}$ electrolyte on titanium electropolishing, Corrosion science 98 (2015) p 494-499, https://doi.org/10.1016/j.corsci.2015.05.0 57

El-Hofy, H. A. (2005). Advanced Machining Processes: Nontraditional and Hybrid Machining Processes, 1st ed. New York: McGraw-Hill. DOI: 10.1036/0071466940

Gu, Y. and Miki, N. (2007). A microfilter utilizing a polyethersulfone porous membrane with nanopores. J. Micromech. Microeng., 17, 2308-2315.

Gu, Y. and Miki, N. (2009). Multilayered microfilter using a nanoporous PES membrane and applicable as the dialyzer of a wearable artificial kidney. J. Micromech. Microeng. 19, 065031. doi:10.1088/0960-1317/19/6/065031

Gu, Y. and Miki, N., (2007), Microfilter Fabricated with PDMS and PES Membrane Applicable for Implantable Artificial Kidney, Proceedings of the 2nd IEEE International Conference on Nano/Micro Engineered and Molecular Systems, IEEE NEMS 2007, 4160441, pp $63-67$.

Gura, V., Rivara, M.B., Bieber, S, dkk, A wearable artificial kidney for patients with end-stage renal disease. JCI Insight. 2016;1(8):e86397. doi:10.1172/jci.insight.86397.

Ito, H., Prihandana, G. S., Sanada, I., Hayashi, M., Kanno, Y., \& Miki, N. (2013). No-dialysate micro hemodialysis system. In17th International Conference on Miniaturized Systems for Chemistry and Life Sciences, MicroTAS 2013. (Vol. 2, 1326-1328). Chemical and Biological Microsystems Society.

Lase, W.N. (2011). Analisis Faktor-Faktor yang Mempengaruhi Kualitas Hidup Pasien Gagal Ginjal Kronis yang Menjalani Hemodialisa di RSUP. H. Adam Malik Medan. Skripsi. Fakultas Keperawatan Universitas Sumatera Utara. Medan.

Mahyudin, F. dan Hermawan H., (2016), Biomaterials and Medical Devices: A Perspective from an Emerging Country, Springer International Publishing, ISBN 978-3-319-14845-8.

Montgomery, D. C., (2009), Design and Analysis of Experiments, 5th ed., John Wiley \& Sons Inc., New York.

National Kidney Foundation, (2002), KDOQI Clinical Practice Guidelines for Chronic Kidney Disease: Evaluation, Classification, and Stratification, Am J Kidney, 39: suppl 1.

Nugroho, Y.B. (2013). pembuatan cnc electro chemical machining serta pengujian permesinan pada pembuatan multi-layered microfilter dengan benda kerja stainless steel 204 
terisolasi. Skripsi. Program Studi Teknik Mesin, Jurusan Teknik Mesin dan Industri Fakultas Teknik Universitas Gadjah Mada. Yogyakarta.

Ota, T., To, N., Kanno, Y., Miki, N. Evaluation of Biofouling for Implantable Micro Dialysis System. Conf Proc IEEE Eng Med Biol Soc, 2016, doi: 10.1109/EMBC.2016.7591103.

Prihandana, G.S., Ito, H., Sanada, I., Nishinaka, Y., Kanno, Y., Miki, N. Permeability and blood compatibility of nanoporous parylene film-coated polyethersufone membrane under long-term blood diffusion. J Appl Polym Sci 2014;131:40024. doi:10.1002/app.40024

Prihandana, G.S., Ito, H., Tanimura, K., Yagi, H., Hori, Y., Soykan, O., dkk. (2014b). Solute diffusion through fibrotic tissue formed around protective cage system for implantable devices. J. Biomed. Mater. Res. B doi:10.1002/jbm.b. 33298

Prihandana, G.S., Mahardika, M., Nishinaka, Y., Ito, H., Kanno, Y., Miki, N., (2013). Electropolishing of Microchannels and its Application to Dialysis System, Journal of Biomanufacturing, p. 165. doi:10.1016/j.procir.2013.01.

Prihandana, G.S., Sanada, I., Ito, H., Noborisaka, M., Kanno, Y., Suzuki, T., Miki, N., (2013). Antithrombogenicity of Fluorinated Diamond-Like Carbon Films Coated Nano Porous Polyethersulfone (PES) Membrane. Materials 2013, 6, 4309-4323; doi: $10.3390 / \mathrm{ma6104309}$

Rosa, J. L., Robin, A., Silva, M. B., Baldan, Carlos A., Peres, Mauro P., (2009), Electrodeposition of copper on titanium wires: Taguchi experimental design approach, Journal of Materials Processing Technology, v. 209, p. 1181-1188.

Sajjad, H. Ling L., Dominique S., Elaine C. D., Sasha O. (2014). Electrochemical polishing as a 316L stainless steel surface treatment method:Towards the improvement of biocompatibility, Corrosion Science 87 (2014) 89-100, http://dx.doi.org/10.1016/j.corsci.2014.06.010

Salim, S., (2016), Analisis Proses Polishing Pada Machining Center, Skripsi, Jurusan Teknik Mesin dan Industri, Fakultas Teknik, Universitas Gadjah Mada, Yogyakarta.

Sawhney, G. S., (2007), Fundamentals of Biomedical Engineering, New Age International (P) Ltd., Publishers ,ISBN (13) : 978-81-224-2549-9

Setyawan, M.A., Sriani, T., and Prihandana, G.S., (2016), Design and Fabrication of MultiLayered Microfilter by Electropolishing Technique, Applied Mechanics and Materials, Vol. 842, pp. 402 - 406.

Setyawan, M.A, (2016), Design and Fabrication of Maze-Shaped Multi-Layered Microfilter Using SS 316L by Electropolishing Technique, Skripsi, Universitas Muhammadiyah Yogyakarta, Yogyakarta.

Silma, A. A., (2017), Perancangan dan Manufaktur Microfilter pada Wearable Artificial Kidney, Skripsi, Jurusan Teknik Mesin dan Industri, Fakultas Teknik, Universitas Gadjah Mada, Yogyakarta.

To, N., Sanada, I., Ito, H., Prihandana, G. S., Morita, S., Kanno, Y., \& Miki, N. (2015). WaterPermeable Dialysis Membranes for Multi-Layered Microdialysis System. Frontiers in Bioengineering and Biotechnology, 3(June), 1-7. https:/ / doi.org/10.3389/fbioe.2015.00070

Voort, G.F.V., (2004), Chemical and Electrolytic Polishing, ASM Handbook, Vol. 9: Metallography and Microstructures, p 281-293, ISBN 978-0-87170-706-2.

Wenten, I.G., Khoiruddin, Aryanti, P.T.P., akim, A.N. (2010). Pengantar Teknologi Membran, Diktat, Departemen Teknik Kimia Institut Teknologi Bandung, Bandung. 